\title{
ANALISA FAKTOR YANG MEMPENGARUHI KEKAMBUHAN PASIEN GANGGUAN JIWA DENGAN MODEL STRES ADAPTASI STUART DI RUMAH SAKIT JIWA DAN KETERGANTUNGAN OBAT SEMBADA MEDAN
}

\author{
M.Dasril Samura1 ${ }^{1}$ TellenMarlinaSihotang ${ }^{2}$ \\ Institut Kesehatan Deli Husada Deli Tua \\ Jl. besar no.77 Delitua Kabupaten Deli Serdang \\ e-mail : coknasamura@gmail.com
}

\begin{abstract}
Mental disorders are very dangerous even it does directly cause death, but will cause deep suffering for the individual and a heavy burden on the family. The factors that cause mental disorders vary depending on the type of mental disorder experienced. This Research aims to determine the factors that affect relapse of mental disorder patients in the Sembada Medan Mental Hospital and Drug Dependency 2019. This research is quantitative with a cross sectional approach and sampling with a purposive sample technique. This research was conducted on 28 respondents with research variables are factors of compliance, family support, and social support. From the research that has been done, it was found that the majority of respondents aged between 31 - 46 years $(64.3 \%)$, based on the sex of the respondents, the majority were male $(60.7 \%)$, based on the environmental characteristics of the majority urban respondents $(64.3 \%)$, based on the family support of the respondents, the majority were good $(57.1 \%)$, based on the respondents' compliance, the majority was not good $(60.7 \%)$, based on environmental support the majority were not good $(67.9 \%))$ The results of the Chi-square test show a significance value of $p$ (0.008) $a<(0.05)$ which means that there are significant factors between adherence, family support, and social support for recurrence in the Mental disorders Hospital and Drug Dependency Medan in 2019. It is recommended for psychiatric patients to be more obedient in taking drugs as recommended by doctors in the Mental sicknes Hospital and Drug Dependency Medan in 2019.
\end{abstract}

\section{Keywords: Compliance, family support, social support}

\section{Pendahuluan}

Gangguan Jiwa Merupakan gangguan dalam fungsi alam pikiran berupa disorganisasi (kekacauan) dalam isi pikiran yang ditandaioleh gejala gangguan pemahaman (waham) gangguan persepsi berupa halusinasi atau ilusi bahkan dijumpai daya nilai realitas terganggu yang ditunjukkan dengan perilaku-perilaku aneh (bizzare). Gangguan ini dijumpai ratarata 1 sampai $2 \%$ dari jumlah seluruh penduduk di suatu wilayah pada setiap waktu dan terbanyak mulai timbul (onset) pada usia 15-35 tahun.( Puspitasari, 2009).

Hasil Survei Kesehatan Mental Rumah Tangga (SKMRT) di Indonesia menyatakan bahwa 264 orang dari 1000 penduduk mengalami gangguan jiwa, 
itu artinya dari satu kepala keluarga terdapat satu anggota keluarga yang mengalami gangguan jiwa dan diperkirakan sejak awal tahun 2009 jumlah penduduk yang mengalami gangguan jiwa sebesar $25 \%$ dari populasi penduduk di Indonesia (Iyus Yosep, 2009).

(Depkes RI, 2008) Mengemukakan $\mathrm{Hal}$ lain yang mempengaruhi keterlambatan penanganan adalah adanya stigma dan diskriminasi terhadap gangguan jiwa. Seperti yang banyak ditemukan pasien gangguan jiwa mengalami pemasungan. Jumlah pemasungan pasien gangguan jiwa di Indonesia adalah sekitar 18.800 kasus.

Alasan peneliti mengambil penelitian ini dan memilih kekambuhan sebagai target populasi dalam penelitian ini didasarkan pada fakta bahwa semakin tingginya angka kejadian gangguan jiwa.Mengingat gangguan jiwa sulit disembuhkan maka potensi pasien yang mengalami kekambuhan akan semakin besar jika tidak ada dukungan yang baik dari pihak rumah sakit, keluarga maupun masyarakat. Berdasarkan hal tersebut, peneliti merasa perlu dan tertarik melakukan penelitian untuk mengetahuifaktor apa saja yangmempengaruhi kekambuhan pada pasien gangguan jiwa. Penelititertarik untuk melakukan penggalian lebih dalam terkait dengan apa yang menyebabkan pasien tersebut mengalami kekambuhan bahkan setelah pasien mendapat perawatan medis maupun psikologis. Peneliti juga berharap bahwa penelitian ini dapat digunakan untuk meminimalkan angka kejadian kekambuhan sehingga dapat menurunkan angka rehospitalisasi pada pasien gangguan jiwa.

\section{Metode Penelitian}

Jenis penelitian ini mengggunakan jenis kuantitatif dengan desain penelitian deskriptif analitik melalui pendekatan cross sectional (belah melintang) yaitu melakukan cross tab antara variabel dependen (kekambuhan) dengan variabel independen (kepatuhan klien, dukungan keluarga dan dukungan lingkungan sekitar). Desain ini dipilih karena tidak ada dilakukan intervensi apapun. Pengukuran dilakukan secara bersamaan kemudian dianalisa kolerasi dari kedua variabel tersebut.

Populasi target pada penelitian ini adalah klien gangguan jiwa yang mengalami kekambuhan yang dirawat di Rumah Sakit Jiwa dan Ketergantungan Obat Sembada Medan.

Sampel dalam penelitian ini adalah bagian dari populasi di ruang rawat inap Rumah Sakit Jiwa dan Ketergantungan Obat Sembada Medan.yang memenuhi kriteria inklusi dan eksklusi. Sampel dipilih dengan metode Purposive sampling, yaitu pengambilan sampel berdasarkan kriteria inklusi(Nursalam 2008), adapun jumlah sampel pada penelitian ini sebanyak 28 orang dari 56 orang jumlah populasi.

\section{Hasil dan Pembahasan}

Berdasarkan hasil pengumpulan data dan pengolahan data yang dilakukan peneliti terhadap Analisa Faktor Yang Mempengaruhi Kekambuhan Pasien Gangguan Jiwa di Rumah Sakit Jiwa Dan ketergantungan Obat Sembada Medan, data menggunakan kuesioner yang dibagikan kepada responden yang termasuk dalam kriteria inklusi yang berada di Rumah Sakit Jiwa Dan ketergantugan Obat Sembada Medan, yang terdiri dari 28 orang responden yang dijadikan sebagai sampel. Analisis pengolahan data menggunakan Program Komputerisasi. 
Analisis Univariat

Tabel 1. Distribusi Frekuensi data responden berdasarkan umur di Rumah Sakit Jiwa dan Ketergantungan Obat Sembada Medan

\begin{tabular}{|c|c|c|}
\hline Usia & Frekuensi & $\begin{array}{l}\text { Persentase } \\
(\%)\end{array}$ \\
\hline $\begin{array}{ll}15 & - \\
30 & \end{array}$ & 2 & $7.1 \%$ \\
\hline $\begin{array}{l}31- \\
46\end{array}$ & 18 & $64.3 \%$ \\
\hline $\begin{array}{l}46- \\
61\end{array}$ & 7 & $25.0 \%$ \\
\hline $\begin{array}{ll}62 & - \\
77 & \end{array}$ & 1 & $3.6 \%$ \\
\hline Total & 28 & 100 \\
\hline
\end{tabular}

diketahui bahwa dari 28 pasien yang ada di Rumah Sakit Jiwa dan Ketergantungan Obat Sembada Medan tahun 2019, disimpulkan bahwa mayoritas responden berada pada umur 31 - 46 tahun dan minoritas umur 62 71 tahun.

Tabel 2. Distribusi Frekuensi data responden berdasarkan jenis kelamin di Rumah Sakit Jiwa dan Ketergantungan Obat Sembada Medan

\begin{tabular}{l|l|l}
\hline $\begin{array}{l}\text { Jenis } \\
\text { kelamin }\end{array}$ & $\begin{array}{l}\text { Frekuen } \\
\text { si }\end{array}$ & $\begin{array}{l}\text { Persentas } \\
\text { e (\%) }\end{array}$ \\
\hline Laki - laki & 17 & $60.7 \%$ \\
\hline $\begin{array}{l}\text { Perempua } \\
\text { n }\end{array}$ & 11 & $39.3 \%$ \\
\hline Total & 28 & 100 \\
\hline \multicolumn{2}{c}{ Berdasarkan Tabel } & 2 dapat
\end{tabular}
diketahui bahwa dari 28 pasien yang ada di Rumah Sakit Jiwa dan Ketergantungan Obat Sembada Medan tahun 2019,disimpulkan bahwa mayoritas responden berjenis kelamin laki - laki sebanyak 17 orang dan minoritas berjenis kelamin perempuan sebanyak 11 orang.

Tabel 3. Distribusi Frekuensi data responden berdasarkan karakteristik lingkungan di Rumah Sakit Jiwa dan Ketergantungan Obat Sembada Medan

\begin{tabular}{l|l|c}
\hline $\begin{array}{l}\text { Lingkunga } \\
\text { n }\end{array}$ & $\begin{array}{l}\text { Frekuen } \\
\text { si }\end{array}$ & $\begin{array}{l}\text { Persentas } \\
\text { e (\%) }\end{array}$ \\
\hline Perkotaan & 18 & $64.3 \%$ \\
\hline $\begin{array}{l}\text { Perdesaa } \\
\text { n }\end{array}$ & 10 & $35.7 \%$ \\
\hline Total & 28 & 100 \\
\hline \multicolumn{2}{c}{ Berdasarkan Tabel } & 4 dapat
\end{tabular}
diketahui bahwa dari 28 pasien yang ada di Rumah Sakit Jiwa dan Ketergantungan Obat Sembada Medan tahun 2019, disimpulkan bahwa mayoritas responden yang memiliki dukungan keluarga baik sebanyak 16 orang dan minoritas yang memiliki dukungan keluarga tidak baik sebanyak 12 orang

Tabel 5. Distribusi Frekuensi data responden berdasarkan kepatuhan klien berobat di Rumah Sakit Jiwa dan Ketergantungan Obat Sembada Medan

\begin{tabular}{l|l|l}
\hline $\begin{array}{l}\text { Kepatuha } \\
\text { n }\end{array}$ & $\begin{array}{l}\text { Frekuen } \\
\text { si }\end{array}$ & $\begin{array}{l}\text { Persentas } \\
\text { e (\%) }\end{array}$ \\
\hline Patuh & 11 & $39.3 \%$ \\
\hline $\begin{array}{l}\text { Tidak } \\
\text { Patuh }\end{array}$ & 17 & $60.7 \%$ \\
\hline Total & 28 & 100 \\
\hline \multicolumn{2}{l}{ Berdasarkan Tabel 5 dapat }
\end{tabular}
diketahui bahwa dari 28 pasien yang ada di Rumah Sakit Jiwa dan Ketergantungan Obat Sembada Medan tahun 2019,disimpulkan bahwa mayoritas responden yang kepatuhan kurang baik sebanyak 17 orang dan minoritas yang kepatuhan baik sebanyak 11 orang

Tabel 6. Distribusi Frekuensi data responden berdasarkan dukungan 
Jurnal Kesehatan Masyarakat \& Gizi,e-ISSN: 2655-0849

Vol. 1 No.2 Edisi November 2018-April 2019

https://ejournal.medistra.ac.id/index.php/JKG

$================================================== \pm$
Received: 18 April 2019 :: Accepted: 27 April 2019 ::Published:29 April 2019

\begin{tabular}{|c|c|c|c|c|c|c|}
\hline \multirow{3}{*}{$\begin{array}{l}\text { Dukung } \\
\text { an sosial }\end{array}$} & \multicolumn{6}{|c|}{ Kekambuuhan } \\
\hline & \multicolumn{2}{|c|}{ Sering } & \multicolumn{2}{|c|}{ jarang } & total & \multirow{2}{*}{$\begin{array}{c}\text { p.val } \\
\text { ue }\end{array}$} \\
\hline & $F$ & $\%$ & $F$ & $\%$ & $\%$ & \\
\hline $\begin{array}{l}\text { Baik } \\
\text { Kurang } \\
\text { baik }\end{array}$ & $\begin{array}{l}1 \\
1 \\
4\end{array}$ & $\begin{array}{l}3,6 \\
\% \\
50 . \\
0 \%\end{array}$ & $\begin{array}{l}8 \\
5\end{array}$ & $\begin{array}{l}28 \\
.6 \\
\% \\
17 \\
.9 \\
\%\end{array}$ & $\begin{array}{l}9 \\
1 \\
9\end{array}$ & $\begin{array}{l}32,1 \% \\
67.9 \% \\
0,003 \\
100,0 \\
\%\end{array}$ \\
\hline TOTAL & $\begin{array}{l}1 \\
5\end{array}$ & $\begin{array}{l}53 . \\
6 \%\end{array}$ & 13 & $\begin{array}{l}46 \\
.4 \\
\% \\
\end{array}$ & $\begin{array}{l}2 \\
8\end{array}$ & \\
\hline
\end{tabular}

tahun 2019 kekambuhan sering sebanyak 15 orang $(53,6 \%)$ dan kekambuhan jarang sebanyak 13 orang $(46,4 \%)$

\section{Analisis Bivariat}

Tabel 8. Faktor dukungan lingkungan sosial terhadap kekambuhan pasien gangguan jiwa di Rumah Sakit Jiwa danKetergantungan Obat Sembada Medan

Dari hasil penelitian faktor lingkungan sosial di Rumah Sakit Jiwa dan Ketergantungan Obat Sembada Medan

\begin{tabular}{l|l|l}
\hline $\begin{array}{l}\text { Dukunga } \\
\text { n social }\end{array}$ & $\begin{array}{l}\text { Frekuens } \\
\text { i }\end{array}$ & $\begin{array}{l}\text { Persentas } \\
\text { e (\%) }\end{array}$ \\
\hline Baik & 9 & $32.1 \%$ \\
\hline $\begin{array}{l}\text { Kurang } \\
\text { baik }\end{array}$ & 19 & $67.9 \%$ \\
\hline Total & 28 & 100 \\
\hline
\end{tabular}
diketahui bahwa dari 28 pasien yang ada di Rumah Sakit Jiwa dan Ketergantungan Obat Sembada Medan tahun 2019, disimpulkan bahwa mayoritas responden dukungan keluarga kurang baik sebanyak 19 orang dan minoritas kepatuhan baik sebanyak 9 orang

Tabel 7. Distribusi Frekuensi data responden berdasarkan frekuensi kekambuhan di Rumah Sakit Jiwa dan Ketergantungan Obat Sembada Medan

\begin{tabular}{l|l|l}
\hline $\begin{array}{l}\text { Kekambuh } \\
\text { an }\end{array}$ & $\begin{array}{l}\text { Frekuen } \\
\text { si }\end{array}$ & $\begin{array}{l}\text { Persenta } \\
\text { se (\%) }\end{array}$ \\
\hline Sering & 15 & $53.6 \%$ \\
\hline Jarang & 13 & $46.4 \%$ \\
\hline Total & 28 & 100 \\
\hline \multicolumn{2}{|c}{ Berdasarkan Tabel 7 dapat }
\end{tabular}

diketahui bahwa dari 28 pasien yang ada di Rumah Sakit Jiwa dan Ketergantungan Obat Sembada Medan 
Dari hasil penelitian faktor dukungan keluarga terhadap kekambuhanpasien gangguan jiwa di Rumah Sakit Jiwa dan Ketergantungan Obat Sembada Medan 2019 diperoleh hasil bahwa responden yang memiliki dukungan keluarga baik sering kambuh sebanyak 4 orang ( $14.3 \%$ ) dan yang jarang kambuh sebanyak 12 orang ( $42.9 \%$ ), responden yang memiliki dukungan keluarga kurang baik sering kambuh sebanyak 11 orang ( $53,6 \%$ ) dan yang jarang kambuh sebanyak 1 orang $(3,65 \%)$. Berdasarkan hasil statistik dengan menggunakan Uji ChiSquare, dari hasil perhitungan diperoleh nilai Pearson Chi-Square diperoleh nilai $p(0,008)<a(0,05)$, maka hipotesa $\mathrm{Ha}$ diterima.Artinya terdapat pengaruh yang signifikan antara dukungan keluarga terhadap terjadinya kekambuhan pasien gangguan jiwa

Tabel 10. Faktor Kepatuhan Minum Obat terhadap kekambuhan pasien gangguan jiwa di Rumah Sakit Jiwa dan Ketergantungan Obat Sembada Medan

Dari hasil penelitian faktor kepatuhan minum obat terhadap kekambuhan pasien gangguan jiwa di Rumah Sakit Jiwa dan Ketergantungan Obat Sembada Medan 2019 diperoleh hasil bahwa responden yang memiliki kepatuhan baik sering kambuh sebanyak 2 orang $(7,1 \%)$ dan yang jarang kambuh sebanyak 9 orang ( $32,19 \%$ ), responden yang memiliki kepatuhan kurang baik sering kambuh sebanyak 13 orang ( $46,4 \%$ ) dan yang jarang kambuh sebanyak 4 orang ( $14,3 \%$ ). Berdasarkan hasil statistik dengan menggunakan Uji Chi-Square, dari hasil perhitungan diperoleh nilai Pearson Chi-Square diperoleh nilai $p$ ( $0,008)<a(0,05)$, maka hipotesa $\mathrm{Ha}$ diterima. Artinya terdapat pengaruh yang signifikan antara kepatuhan terhadap terjadinya kekambuhan pasien gangguan jiwa.

\begin{tabular}{|c|c|c|c|c|c|c|c|}
\hline \multirow{3}{*}{$\begin{array}{l}\text { Dukung } \\
\text { an } \\
\text { keluarg } \\
\text { a }\end{array}$} & \multicolumn{7}{|c|}{ Kekambuhan } \\
\hline & \multicolumn{2}{|c|}{ Sering } & \multicolumn{2}{|c|}{ Jarang } & \multicolumn{2}{|c|}{ total } & \\
\hline & $\mathrm{F}$ & $\%$ & $\mathrm{~F}$ & & $F$ & & \\
\hline $\begin{array}{l}\text { Baik } \\
\text { Kurang } \\
\text { baik }\end{array}$ & $\begin{array}{l}4 \\
1 \\
1\end{array}$ & $\begin{array}{l}14 . \\
3 \\
\% \\
39 . \\
3 \\
\%\end{array}$ & $\begin{array}{l}1 \\
2 \\
1\end{array}$ & $\begin{array}{l}42 \\
.9 \\
\% \\
3 . \\
6 \\
\%\end{array}$ & $\begin{array}{l}1 \\
6 \\
1 \\
2\end{array}$ & $\begin{array}{l}57 \\
\% \\
42 \\
\% \\
0,\end{array}$ & $\begin{array}{l}7.1 \\
2.9 \\
001\end{array}$ \\
\hline TOTAL & $\begin{array}{l}1 \\
5\end{array}$ & $\begin{array}{l}53 . \\
6 \\
\%\end{array}$ & $\begin{array}{l}1 \\
3\end{array}$ & $\begin{array}{l}46 \\
.4 \\
\%\end{array}$ & $\begin{array}{l}2 \\
8\end{array}$ & & 0,0 \\
\hline
\end{tabular}

Faktor Dukungan Lingkungan Sosial terhadap kekambuhan pasien gangguan jiwa

Dari hasil penelitian Analisa Faktor yang mempengaruhi kekambuhan pasien gangguan jiwa di Rumah Sakit Jiwa dan Ketergantungan Obat Sembada Medan 2019 diperoleh hasil bahwa responden yang memiliki dukungan sosial baik sering kambuh sebanyak 1 orang ( $3,6 \%)$ dan yang jarang kambuh sebanyak 8 orang ( $28,6 \%)$ ), responden yang memiliki dukungan sosial kurang baik sering kambuh sebanyak 14 orang ( $50,0 \%$ ) dan yang jarang kambuh sebanyak 5 orang $(17,9 \%)$. Berdasarkan hasil statistik dengan menggunakan $\mathrm{Uji}$ ChiSquare, dari hasil perhitungan diperoleh nilai Pearson Chi-Square diperoleh nilai $p(0,008)<a(0,05)$, maka hipotesa Ha diterima. Artinya terdapat pengaruh yang signifikan antara dukungan sosial

\begin{tabular}{|c|c|c|c|c|c|c|c|}
\hline \multirow{3}{*}{$\begin{array}{l}\text { Kepa } \\
\text { tuha } \\
\text { n }\end{array}$} & \multicolumn{7}{|c|}{ Kekambuhan } \\
\hline & \multicolumn{2}{|c|}{ sering } & \multicolumn{2}{|c|}{ Jarang } & \multicolumn{2}{|c|}{ total } & \multirow{2}{*}{$\begin{array}{l}P \\
\text { va } \\
\text { lu } \\
\text { e }\end{array}$} \\
\hline & $\mathrm{F}$ & $\%$ & $\mathrm{~F}$ & $\%$ & $\mathrm{~F}$ & $\%$ & \\
\hline $\begin{array}{l}\text { Patuh } \\
\text { Tidak } \\
\text { Patuh }\end{array}$ & $\begin{array}{l}2 \\
13\end{array}$ & $\begin{array}{l}7.1 \\
\% \\
46 . \\
4 \%\end{array}$ & $\begin{array}{l}9 \\
4\end{array}$ & $\begin{array}{l}32 . \\
1 \% \\
14 . \\
3 \%\end{array}$ & $\begin{array}{l}1 \\
1 \\
1 \\
7\end{array}$ & $\begin{array}{l}35 \\
\% \\
60 \\
\% \\
0\end{array}$ & $\begin{array}{l}.3 \\
.7 \\
006\end{array}$ \\
\hline $\begin{array}{l}\text { TOTA } \\
\text { L }\end{array}$ & 15 & $\begin{array}{l}53 . \\
6 \\
\%\end{array}$ & $\begin{array}{l}1 \\
3\end{array}$ & $\begin{array}{l}46 . \\
4 \%\end{array}$ & 8 & & \\
\hline
\end{tabular}


terhadap terjadinya kekambuhan pasien gangguan jiwa.

Dari hasil penelitian Distribusi frekuensi berdasarkan karakteristik lingkungan pasien gangguan jiwa di Rumah Sakit Jiwa dan Ketergantungan Obat Sembada Medan 2019 diperoleh hasil bahwa responden yang tinggal di perkotaan sebanyak 18 orang ( $64,3 \%$ ). Dan yang tinggal di lingkungan pedesaan sebanyak 10 orang ( $35,7 \%$ ). Jadi dapat disimpulkan bahwa mayoritas responden yang tinggal di perkotaan sebanyak 18 orang

Faktor dukungan keluarga terhadap kekambuhan pasien gangguan jiwa

Dari hasil penelitian Analisa Faktor yang mempengaruhi kekambuhan pasien gangguan jiwa di Rumah Sakit Jiwa dan Ketergantungan Obat Sembada Medan 2019 diperoleh hasil bahwa responden yang memiliki dukungan keluarga baik sering kambuh sebanyak 4 orang ( $14.3 \%$ ) dan yang jarang kambuh sebanyak 12 orang ( $42.9 \%$ ), responden yang memiliki dukungan keluarga kurang baik sering kambuh sebanyak 11 orang ( 53,6\% ) dan yang jarang kambuh sebanyak 1 orang $(3,65 \%)$. Berdasarkan hasil statistik dengan menggunakan Uji ChiSquare, dari hasil perhitungan diperoleh nilai Pearson Chi-Square diperoleh nilai $p(0,008)<a(0,05)$, maka hipotesa Ha diterima. Artinya terdapat pengaruh yang signifikan antara dukungan keluarga terhadap terjadinya kekambuhan pasien gangguan jiwa.

Menurut Kurnia Kusuma (2009), Dukungan keluarga merupakan salah satu sumber penanganan gangguan jiwa yang penting dan mempunyai pengaruh terhadap kondisi kesehatan seseorang .Hal ini sejalan dengan penelitian Saputrs Nanda(2010), Dalam penelitiannya yang menjelaskan bahwa adanya pengaruh antara dukungan keluarga terhadap kekambuhan pasien gangguan jiwa dengan nilai $p=0,015$ value $(p<0,05)$

\section{Faktor kepatuhan klien minum obat terhadap kekambuhan pasien gangguan jiwa}

$\begin{array}{rrr} & \text { Dari hasil penelitian Analisa } \\ \text { Faktor } & \text { yang } & \text { mempengaruhi }\end{array}$ kekambuhan pasien gangguan jiwa di Rumah Sakit Jiwa dan Ketergantungan Obat Sembada Medan 2019 diperoleh hasil bahwa responden yang memiliki kepatuhan baik sering kambuh sebanyak 2 orang $(7,1 \%)$ dan yang jarang kambuh sebanyak 9 orang ( $32,19 \%$ ), responden yang memiliki kepatuhan kurang baik sering kambuh sebanyak 13 orang ( $46,4 \%$ ) dan yang jarang kambuh sebanyak 4 orang ( $14,3 \%$ ). Berdasarkan hasil statistik dengan menggunakan Uji Chi-Square, dari hasil perhitungan diperoleh nilai Pearson Chi-Square diperoleh nilai $p$ ( $0,008)<a(0,05)$, maka hipotesa $\mathrm{Ha}$ diterima. Artinya terdapat pengaruh yang signifikan antara kepatuhan terhadap terjadinya kekambuhan pasien gangguan jiwa.

Menurut Kurnia Kusuma (2009), Minum obat yang teratur dapat mengurangi kekambuhan, namun penggunaan obat neuroleptik dalam jangka panjang dapat menimbulkan efek samping yang dapaat menganggu hubungan sosial seperti gerakan yang tidak terkontrol.

Hal penelitian ini sejalan dengan Simatupang (2014), Yang menjelaskan bahwa yang paling banyak menyebabkan kekambuhan pada pasien gangguan jiwa adalah karena faktor ketidak patuhan minum obat.Pitoyo(2010) dari hasil uji statistik diketahui bahwa ada pengaruh yang signifikan antara ketaatan minum obat pasien gangguan jiwa terhadap kekambuhan pada pasien gangguan jiwa. 


\section{Kesimpulan}

Penelitianfaktor

yang mempengaruhi kekambuhan pasien gangguan jiwa di Rumah Sakit Jiwa Dan ketergantungan Obat Sembada Medan.Hasil ini dapat di simpulkan sebagai berikut :

1).Terdapat pengaruh dukungan keluarga terhadap kekambuhan pasien gangguan jiwa di Rumah Sakit Jiwa Dan ketergantungan Obat Sembada Medan 2019. disimpulkan bahwa mayoritas responden yang memiliki dukungan keluarga baik sebanyak 16 orang ( $57,1 \%$ ).

2).Terdapat pengaruh kepatuhan klien berobat terhadap kekambuhan pasien gangguan jiwa di Rumah Sakit Jiwa Dan ketergantungan Obat Sembada Medan 2019. Disimpulkan bahwa mayoritas responden yang kepatuhan kurang baik sebanyak 17 orang ( $60.7 \%$ ).

3). Terdapat pengaruh dukungan lingkungan sekitar terhadap kekambuhan pasien gangguan jiwa di Rumah Sakit Jiwa Dan ketergantungan Obat Sembada Medan. Dapat disimpulkan bahwa mayoritas responden dukungan keluarga kurang baik sebanyak 19 orang ( $67.9 \%)$.

\section{DAFTAR PUSTAKA}

Adi.2012. Gambaran Karakterestik Klien Yang Di Rawat Di Rumah Sakit Khusus DaerahProvinsi Sulawesi

Selatan.http://www.4skripsi.com. html. [acc essed 20 Oktober 2018]

Agus, Dwi 2014. Faktor-faktor Yang Mempengaruhi Kekambuhan Pada Pasien Skizofrenia di RSJD dr. AMINO GONDOHUTOMO SEMARANG [acc essed 13 Oktober 2018]

Depkes RI. (2008). Riset Kesehatan Dasar 2007. Jakarta: Badan Penelitian dan Pengembangan Kesehatan

Dewi \& Marchira. 2009. Riwayat Gangguan Jiwa Pada Keluarga Dengan Kekambuhan Pasien
Skizofrenia Di Rsup Dr Sardjito Yogyakarta. [acc essed 15 Oktober 2018]

Keliat, Budi. 2009. Peran Serta Keluarga Dalam Perawatan Klien Gangguan Jiwa. Jakarta : EGC

Maslim.R2002.Gejala Depresi, Diagnosa Gangguan Jiwa Rujukan Ringkas DariPPDGJ-III.Jakarta : Bagian IlmuKedokteran Jiwa FKUnika Atmajaya.

Muhlisin abi 2018. Keperawatan Keluarga, Yogyakarta : Gosyen Publishing

Rasmun, 2001. Keperawatan Kesehatan Mental Psikatri terintegrasi Dengan Keluarga . Edisi I. Jakarta : CV. Sagung Seto Siahaan, C. 2012. SkripsiFaktor-Faktor YangMempengaruhi KetidakpatuhanMinum Obat Pasien Skizofrenia Yang Mengalami. Keperawatan USU. [acc essed 15 Oktober 2018]

Sirait\& Mustika. 2009. Faktor-Faktor Penyebab Ketidakpatuhan Pasien Skizofrenia Menjalani Pengobatan Dirumah Sakit Jiwa Daerah Propinsi Sumatera Utara Medan. [acc essed 20 Oktober 2018]

Sugiono, 2009. Metode Penelitian Kuantitatif , Kualitatif dan R\&G . Bandung : CV Alvabeta

Suliswati.(2005). Konsep Dasar Keperawatan Jiwa. Jakarta: EGC.

Suprajitno, 2018. Asuhan Keperawatan Keluarga. Jakarta : Buku kedokteran EGC

Survei Kesehatan Rumah Tangga (SKRT), 2007. Kesehatan Indonesia. Jakarta.

Sutejo 2017. Keperawatan Kesehatan Jiwa.Yogyakarta : pustaka baru press

Videbeck, Sheila L. 2008. Buku Ajar Keperawatan JiwaJakarta : EGC.

Yosep, I. 2007.Keperawatan Jiwa. Bandung : Refika Aditama.

Yosep, Iyus. (2008).Faktor Penyebab dan Proses terjadinya Gangguan Jiwa http://resources.unpad.ac.id/ [acc essed 22 Oktober 2018] 